\title{
SISTEM INFORMASI PENERIMAAN SISWA BARU DI SMA NEGERI 6 TASIKMALAYA
}

\author{
Oleh \\ Nursyamsi \\ Politeknik Triguna Tasikmalaya \\ nursyamsi@yahoo.com
}

\begin{abstract}
Abstrak - Tujuan dari pembuatan sistem ini adalah untuk membantu kinerja panitia siswa baru dalam proses pengolahan data penerimaan siswa baru yang lebih efektif dan efisien. Metode penelitian yang digunakan dalam penelitian ini adalah metode penelitian deskriptif, sedangkan metode pengembangan sistem informasi yang digunakan adalah System Development Life Cycle (SDLC) dengan tahapan; analisa sistem, desain sistem, implementasi sistem, operasi dan pemeliharaan. Hasil penelitian ini menunjukan bahwa sistem yang diusulkan menggunakan Visual Basic .Net 2008 dan Ms. Access yang penulis buat benar-benar telah terbukti dapat membantu mempermudah dan memperlancar sistem informasi penerimaan siswa baru di SMA Negeri 6 Tasikmalaya.
\end{abstract}

Kata Kunci : Sistem Informasi, Penerimaan, Siswa baru di SMA Negeri 6 Tasikmalaya.

\begin{abstract}
The purpose of this system product is to help the new student committee's performance in data processing of the new student admission more effective and efficient. The research method which was used in this research is descriptive method, whilst the development of information system method which was used is System Development Life Cycle (SDLC) the steps are; system analysed, system design, system implementation, operation and preservation. The result of the research has been showed that the system which was proposed used Visual Basic. Net 2008 and Ms. Access was made by the writer. It has been absolutely provento help, to facilitate and to accelerate of information system in new student admission at SMA Negeri 6 Tasikmalaya.
\end{abstract}

Keyword : Information system, admission, new student at SMA Negeri 6 Tasikmalaya.

\section{Pendahuluan}

Penerimaan Siswa Baru ( PSB ) merupakan serangkaian kegiatan yang dilakukan oleh beberapa lemabaga pendidikan yang berbentuk formal, khususnya sekolah negeri maupun swasta setiap pergantian tahun ajaran baru. Penerimaan siswa baru yang diadakan oleh pihak sekolah memungkinkan adanya ratusan calon siswa yang mendaftar masuk ke jenjang pendidikan yang lebih tinggi. Dalam hal ini pihak sekolah membentuk panitia penerimaan siswa baru untuk memudahkan proses pendaftaran.

SMA Negeri 6 Tasikmalaya merupakan sekolah menengah atas yang ada di Kabupaten Tasikmalaya. Sekolah ini memiliki dua jurusan bidang studi diantaranya IPA dan IPS. Dalam mempertahankan eksistensinya pihak sekolah setiap awal tahun ajaran baru membuka penerimaan siswa baru. Dalam pelaksanaannya, kegiatan tersebut menghadapi berbagai masalah antara lain, kesalahan dalam penginputan beberapa data yang sulit dibaca, kesulitan dalam menentukan ranking dari tiap pendaftar, karena 
Perwira Journal of Science and Engineering (PJSE)

E-ISSN : XXXX-XXX

Volume 1 Nomor 1

Februari 2021

menggunakan tulisan tangan, serta lamanya proses pembuatan laporan seleksi penerimaan siswa baru kepada kepala sekolah.untuk mendapatkan informasi yang dibutuhkannya. Permasalahan yang terjadi:

1. Bagaimana sistem informasi yang sedang berjalan mengenai Penerimaan Siswa Baru di SMA Negeri 6 Tasikmalaya?

2. Bagaimana sistem informasi yang diusulkan untuk Penerimaan Siswa Baru di SMA Negeri 6 Tasikmalaya agar lebih efektif dan efisien ?

Mengingat luasnya kemungkinan pembahasan topik yang diambil, maka penulis membatasi ruang lingkup pembahasan agar tujuan penelitian lebih terarah dan dapat tercapai. diantaranya :

1. Sistem informasi hanya meliputi pengolahan data penerimaan siswa baru.

2. Laporan yang dihasilkan diantaranya:

a. Laporan pendaftar peserta didik baru.

b. Laporan peserta didik baru yang diterima berdasarkan nilai.

c. Laporan peserta didik baru yang diterima berdasarkan asal sekolah.

d. Laporan distribusi peserta didik baru tiap jurusan.

e. Laporan perkembangan pendaftar calon peserta didik baru tiap tahun ajaran.

3. Bahasa pemograman yang digunakan adalah Visual Studio VB. Net 2008 dan Databasenya menggunakan Ms. Access.

\section{Metode Pengembangan Sistem}

Metode pengembangan sistem yang digunakan oleh penulis yaitu SDLC ( System Development Life Cycle ). Menurut Abdul Khadir ( 2003 : 398 ) "SDLC ( System Development Life Cycle) merupakan metodologi klasik yang digunakan untuk mengembangkan, memelihara, dan menggunakan sistem informasi”.

Tahapan - tahapan dalam proses pengembangan sistem ini harus diselesaikan terlebih dahulu sebelum melanjutkan ke tahap berikutnya. Tahapan - tahapan dengan model waterfall ( model air terjun ) yaitu analisis sistem, desain sistem, implementasi sistem, operasi dan pemeliharaan. Tahapan - tahapan tersebut dapat dijelaskan sebagai berikut :

1. Analisis Sistem

Analisis sistem dimulai karena adanya permintaan terhadap sistem baru, dengan maksud mengembangakan sistem yang sudah ada atau mengatasi masalah - masalah yang belum tertangani dan memungkinkan untuk menentukan solusi bagi perusahaan. Analisis sistem mencakup studi kelayakan dan analisis kebutuhan.

a. Studi kelayakan

Studi kelayakan ini digunakan untuk memastikan apakah solusi yang diusulkan dapat dicapai dengan sumber daya dan memperhatikan resiko - resiko dalam perusahaan serta dampak lingkungan terhadap lingkungan di sekitarnya.

b. Analisis Kebutuhan

Analisis kebutuhan dilakukan untuk menghasilkan spesifikasi yang rinci tentang apa yang akan dilakukan sistem ketika diimplementasikan, serta dipakai untu membuat kesepakatan antara pengembang sistem dan pemakai sistem. Dalam melakukan analisis kebutuhan, analis sistem melakukan langkah - langkah seperti wawancara, riset sistem yang terjadi sekarang, observasi lapangan untuk mengetahui sistem yang sedang berjalan, kuis, serta pengamatan terhadap sistem serupa pada tempat lain. 
Perwira Journal of Science and Engineering (PJSE)

E-ISSN : XXXX-XXX

Volume 1 Nomor 1

Februari 2021

2. Desain sistem

Desain sistem dilakukan untuk menghasilkan rancangan yang dapat memenuhi kebutuhan yang diinginkan selama tahapan analisis sistem, menghasilkan spesifikasi sistem yang rinci sehingga mudah diwujudkan saat pemrograman.

3. Implementasi sistem

Implementasi sistem adalah suatu aktivitas yang dilakukan untuk menguji sistem yang telah dibuat, dalam bentuk pemrograman ataupun sistem baru yang telah dilakukan. Dalam hal ini aktivitas yang dilakukan diantaranya membangun komponen komponen perangkat lunak, melakukan verifikasi dan pengujian sistem, mengkonversi data yang digunakan untuk mengoperasikan sistem baru, melakukan dokumentasi yang nantinya akan menjadi acuan pada tahap proses operasi dan pemeliharaan dan menginstal sistem baru.

4. Operasi dan pemeliharaan

Pada tahap ini sistem baru yang telah berjalan sepenuhnya menggantikan sistem lama memasuki tahapan operasi dan pemeliharaan. Pemeliharaan dilakukan karena pada sistem baru masih menyisakan masalah - masalah yang tidak terdeteksi selama masa pengujian berlangsung, terjadi perubahan prosedur dalam bisnis atau adanya permintaan kebutuhan baru oleh pengguna sistem, serta kinerja sistem yang menjadi menurun sehingga terjadi perubahan - perubahan dalam penulisan program.

\section{Kajian Teoritis}

Menurut Tata Sutabri ( $2005: 8$ ) "Suatu sistem pada dasarnya adalah sekelompok unsur yang erat hubungannya satu dengan yang lain, yang berfungsi bersama - sama untuk mencapai tujuan tertentu".

\section{Pengertian Informasi}

Menurut Gordon B. Davis ( 2002 : 28 ) "Informasi adalah data yang telah diolah menjadi sebuah bentuk yang berarti bagi penerimanya dan bermanfaat dalam mengambil keputusan saat ini atau mendatang".

\section{Pengertian Sistem Informasi}

Menurut Tata Sutabri ( $2005: 42$ ) "SISTEM INFORMASI adalah suatu sistem di daalm suatu organisasi yang mempertemukan kebutuhan pengolahan transaksi harian yang mendukung fungsi operasi organisasi yang bersifat manajerial dengan kegiatan strategi dari suatu organisasi untuk dapat menyediakan kepada pihak luar tertentu dengan laporan - laporan yang diperlukan".

\section{Pengembangan Sistem}

\section{a. Metode Pendekatan Sistem}

Menurut Tata Sutabri ( 2005 : 294 ) Terdapat beberapa pendekatan yang ada untuk mengembangkan sistem informasi, yaitu :

1) Pendekatan Klasik.

2) Pendekatan Terstruktur.

3) Pendekatan Bottom Up dan Top Down.

\section{b. Metode Pengembangan Sistem}

Metode pengembangan sistem adalah suatu metode yang digunakan atau diikuti oleh organisasi, instansi, dan lembaga - lembaga pemerintahan dalam menganalisa, merancang, mengimplementasikan, dan memelihara sistem informasi. 
Perwira Journal of Science and Engineering (PJSE)

E-ISSN : XXXX-XXX

Volume 1 Nomor 1

Februari 2021

Menurut Abdul Khadir ( 2003 : 398 ) "SDLC ( System Development Life Cycle ) merupakan metodologi klasik yang digunakan untuk mengembangkan, memelihara, dan menggunakan sistem informasi”.

Jumlah tahapan SDLC dalam berbagai literatur berbeda - beda, namun pada prinsipnya secara keseluruhan semua proses yang dilakukan sama. Tahapan - tahapan pengembangan sistem dalam SDLC yaitu :

1. Analisis Sistem,

2. Desain,

3. Implementasi,

4. Operasi Dan Pemeliharaan.

\section{c. Alat Bantu Analisis}

1. Flow Map berikut :

Definisi Flowmap menurut Ladjamudin bin Al-Bahra ( 2005 : 62 ) adalah sebagai

"Flowmap adalah bagan-bagan yang mempunyai arus yang menggambarkan langkah-langkah penyelesaian suatu masalah. Flowmap merupakan cara penyajian dari suatu algoritma".

\section{Diagram Kontek}

Menurut Winarno ( 2006 : 10.11 ) "Diagram konteks adalah DFD yang paling awal dibuat. DFD ini sering disebut dengan DFD level 0. Di dalam DFD level 0, belum dimunculkan lambing table atau file data".

\section{Data Flow Diagram}

Menurut Winarno ( 2006 : 10.8 ) "Diagram aliran data atau data flow diagram (DFD) adalah diagram yang digunakan untuk menggambarkan aliran data dan informasi dalam suatu sistem".

\section{Kamus Data}

Kamus data berfungsi membantu pengguna sistem untuk mengartikan aplikasi secara detail dan mengorganisasi semua elemen data yang digunakan dalam sistem sehingga pemakai dan penganalisa sistem mempunyai dasar pengertian yang sama tentang masukan, keluaran, penyimpanan dan proses.

\section{Perancangan Basis Data}

Merancang basis data merupakan suatu hal yang sangat penting. Kesulitan utama dalam merancang basis data adalah bagaimana merancang basis data dapat memuaskan keperluan saat ini dan masa yang akan datang.

\subsection{Penerimaan Siswa Baru}

Penerimaan siswa baru merupakan upaya instansi sekolah untuk memperoleh calon siswa baru yang sesuai dengan kriteria setiap sekolah, dan proses seleksi akademis calon siswa untuk menuju jenjang pendidikan yang lebih tinggi dalam tingakatan pendidikan.

\subsection{Visual Studo 2008 dan VB .Net}

\subsubsection{Pengertian Visual Studio 2008}

Menurut Edy Winarno, dkk dalam buku Pemrograman Visual Basic.net untuk Aplikasi Office menerangkan bahwa " Ditahun 2007, 19 November perusahaan Microsoft merilis Visual Studio 2008 dengan dirilisnya Microsoft Visual C\# , Visual Basic .Net, Microsoft C++ 2008, dan Microsoft . Net Framework 3.5. Visual Studio 2008 memiliki versi NET Framework 3.5 , versi Common Language Runtime ( CLR ) 2.0 dan menambahkan fitur terbaru seperti website yang AJAX - enabled Web site dan LINQ ( 
Perwira Journal of Science and Engineering (PJSE)

E-ISSN : XXXX-XXX

Volume 1 Nomor 1

Februari 2021

Language Intergrated Query ). Di update SP1 ada tambahan .NET Framework Client Profile, Dynamic Data, dan tambahan kecil lainnya".

\subsection{2 .Net Framework}

Menurut Wahana Komputer ( $2006: 3$ ) “.Net Framework adalah sebuah framework atau bingkai kerja bagi aplikasi - aplikasi .Net yang dibuat menggunakan Visual Studio .Net tanpa terpengaruh bahasa pemrograman yang digunakan".

\subsubsection{Pengertian VB .Net}

VB. Net ( Visual Basic .Net) adalah sebuah bahasa pemrograman yang berorientasi pada objek yang dikembangkan oleh Microsoft dan menjadi salah satu bahasa pemrograman yang mendukung .Net programming melalui Visual Studio.

\subsection{Database}

\subsubsection{Pengertian Database}

Menurut Tata Sutabri ( 2005 : 161 ) "Database adalah suatu kumpulan data terhubung ( interrelated data ) yang disimpan secara bersama - sama pada suatu media, tanpa mengatap satu sama lain atau tidak perlu suatu kerangkapan data ( controlled redundancy ) dengan cara tertentu sehingga mudah digunakan atau ditampilkan kembali; dapat digunakan oleh satu atau lebih program aplikasi secara optimal; data disimpan tanpa mengalami ketergantungan pada program yang akan menggunakannya; data disimpan sedemikian rupa sehingga penambahan, pengembalian, dan modifikasi dapat dilakukan dengan mudah dan terkontrol".

\subsubsection{Database Manager System ( DBMS )}

Menurut Tata Sutabri (2005 : 174 ) "Database Management System (DBMS) adalah perangkat lunak yang memberi fasilitas (yang tersedia dan dapat digunakan) untuk melakukan fungsi pengaturan, pengawasan, pengendalian/control, pengolahan, dan koordinasi terhadap semua proses/operasi yang terjadi pada system database".

\subsubsection{Microsoft Access 2007}

Microsoft Access 2007 merupakan perangkat lunak system manajemen database relasional dan berorientasi visual, serta berbasis Windows. Fungsi kinerja utamanya digunakan untuk membuat dan memodifikasi table, formulir entri data, query, laporan, dan database.

\section{Metode Penelitian}

Metode penelitian yang digunakan oleh penulis yaitu metode penelitian deskriptif. Metode deskriptif yaitu metode pembahasan masalah yang digunakan untuk menggambarkan objek yang diteliti dengan cara mengumpulkan data dan menganalisa data yang diperoleh lalu diambil sebuah kesimpulan.

\subsubsection{Metode Pengumpulan Data}

\section{Observasi}

Dilakukan dengan mengadakan penelitian langsung dengan pihak sekolah untuk mengumpulkan informasi dan data yang dibutuhkan.

\section{Wawancara}

Dilakukan dengan tanya jawab dengan panitia penerimaan siswa baru di SMA Negeri

6 Tasikmalaya untuk mengetahui gambaran sistem yang sedang berjalan.

\section{Studi Pustaka}

Dilakukan dengan membaca dan mempelajari buku-buku yang terkait dengan masalah, serta mencari dan mempelajari dari media internet. 
Perwira Journal of Science and Engineering (PJSE)

E-ISSN : XXXX-XXX

Volume 1 Nomor 1

Februari 2021

\section{Analisa Masalah}

\subsection{Analisa Dokumen}

Dokumen yang digunakan pada Sistem Informasi Penerimaan Siswa Baru di SMA Negeri 6 Tasikmalaya adalah sebagai berikut :

1. Data pendaftar calon siswa baru

2. Data nilai

3. Data matpel ( mata pelajaran )

4. Data asal sekolah

5. Data kelas

\subsection{Diagram Alir Dokumen}

Analisa dokumen merupakan kegiatan pengumpulan informasi untuk mengklasifikasikan dokumen-dokumen yang digunakan dalam suatu sistem. Tujuan dari analisa dokumen ini yaitu untuk mengetahui dan memahami dokumen - dokumen apa saja yang terlibat dan mengalir dalam sistem yang sedang berjalan.

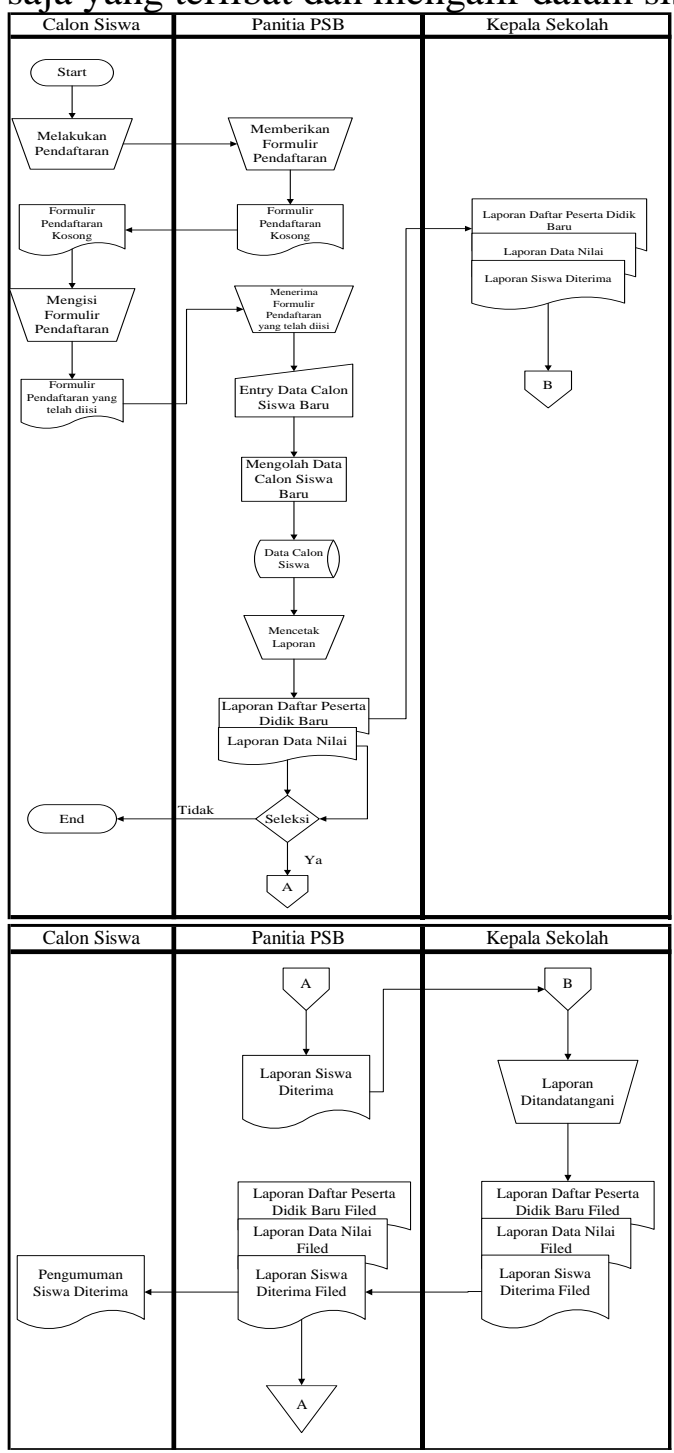

Gambar 1. DAD yang sedang berjalan 
Perwira Journal of Science and Engineering (PJSE)

E-ISSN : XXXX-XXX

Volume 1 Nomor 1

Februari 2021

\section{Hasil Penelitian dan Pembahasan}

\subsection{Flowchart Yang Diusulkan}

Menurut Winarno ( $2006: 10.2$ ) "Flowchart ( bagan aliran ) adalah gambar yang menggunakan lambang - lambang baku untuk menggambarkan sistem atau proses". Flowchart yang diusulkan dapat digambarkan sebagai berikut :

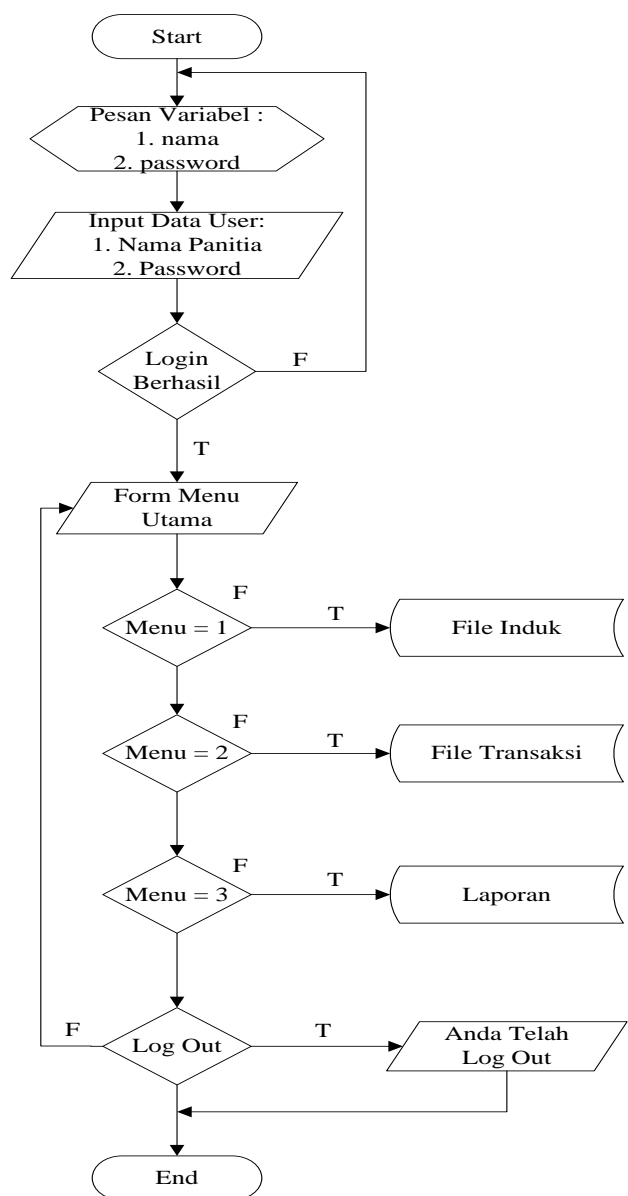

Gambar 2. Flowchart Menu Utama

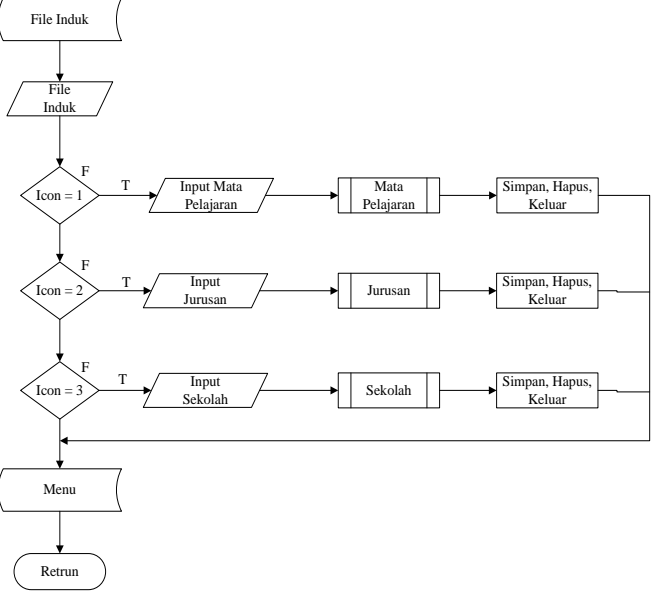

Gambar 3. Flowchart File Induk 
Perwira Journal of Science and Engineering (PJSE)

E-ISSN : XXXX-XXX

Volume 1 Nomor 1

Februari 2021

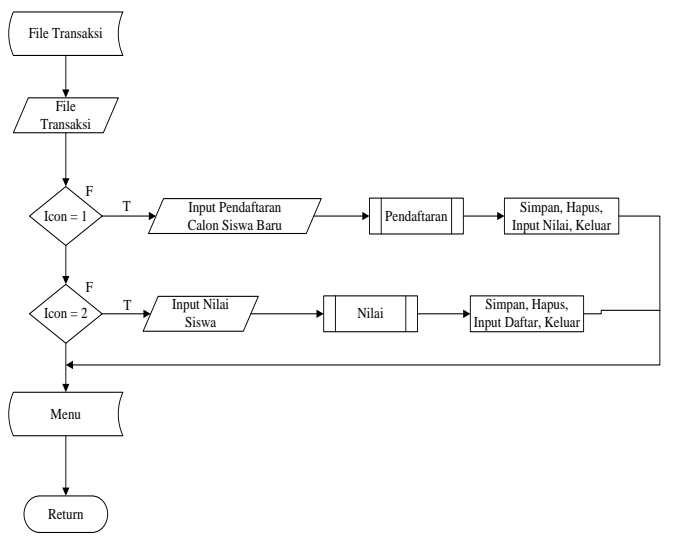

Flowchart File Transaksi

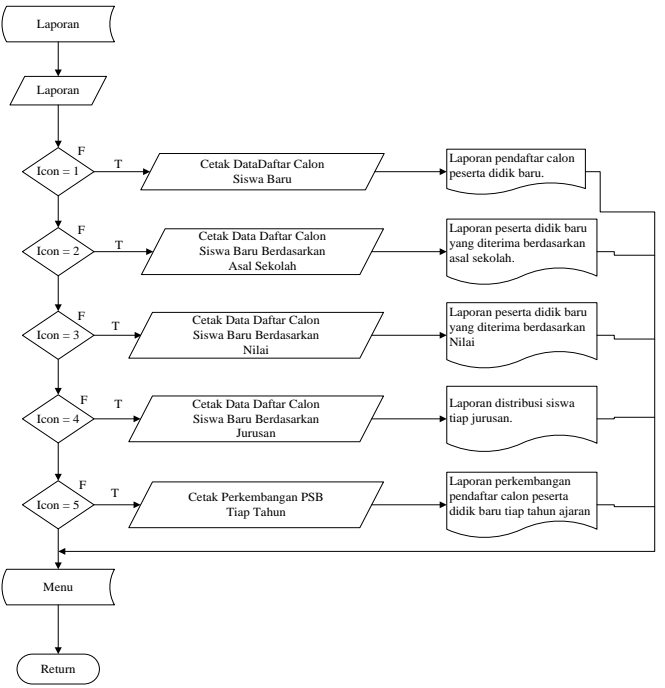

Gambar 4. Flowchart Laporan

\subsection{Diagram Context}

Diagram konteks adalah diagram yang terdiri dari suatu proses dan menggambarkan ruang lingkup suatu sistem. Diagram konteks merupakan level tertinggi dari DFD yang menggambarkan seluruh input ke sistem atau output sistem.

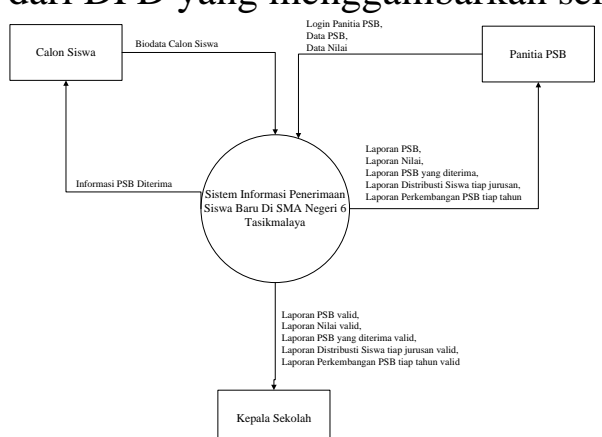

Gambar 5. Diagram Context Sistem Informasi Penerimaan Siswa Baru Di SMA Negeri 6 Tasikmalaya. 
Perwira Journal of Science and Engineering (PJSE)

E-ISSN : XXXX-XXX

Volume 1 Nomor 1

Februari 2021

\subsection{Data Flow Diagram ( DFD )}

\subsubsection{DFD Level 0}

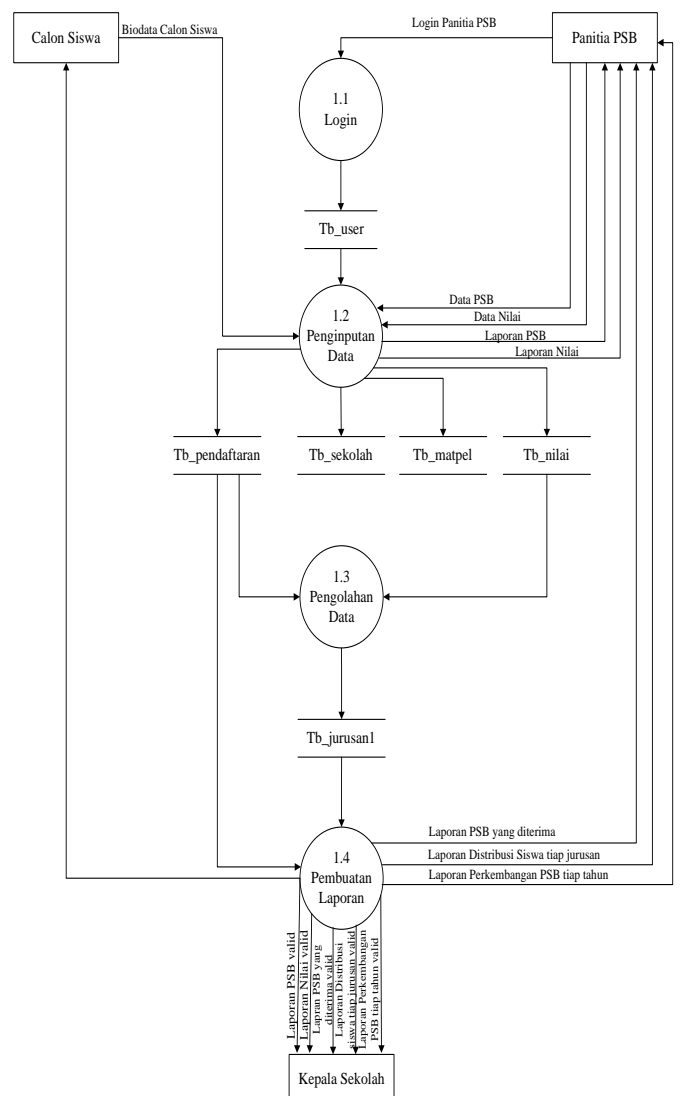

Gambar 6. DFD Level 0 Sistem Informasi Penerimaan Siswa Baru Di SMA Negeri 6 Tasikmalaya.

\subsection{Entity Relationship Diagram (ERD)}

Menurut Sutanta (2011: 91) "Entity Relationship Diagram (ERD) merupakan suatu model data yang dikembangkan berdasarkan objek". ERD digunakan untuk memodelkan struktur data dan hubungan antar data.

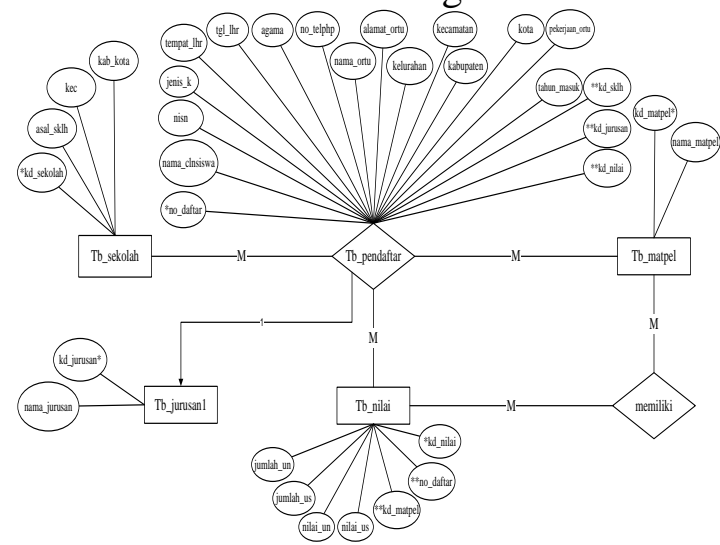

Gambar 7. ER- Diagram Sistem Informasi Penerimaan Siswa Baru Di SMA Negeri 6 Tasikmalaya. 
Perwira Journal of Science and Engineering (PJSE)

E-ISSN : XXXX-XXX

Volume 1 Nomor 1

Februari 2021

\subsection{Kamus Data}

Kamus data adalah rincian fakta tentang data dan kebutuhan - kebutuhan informasi dari suatu sistem informasi yang disimpan didalam basis data dan dikendalikan oleh sistem manajemen basis data. Kamus data dari sistem yang diusulkan adalah :

1. Tabel Pendaftaran

\begin{tabular}{|l|l|l|l|}
\hline Field Name & Data Type & Size & Deskripsi \\
\hline no_daftar & Text & 5 & Nomor Daftar \\
\hline nama_clnsiswa & Text & 30 & Nama Calon Siswa \\
\hline nisn & Text & 30 & NISN \\
\hline jenis_k & Text & 1 & Jenis Kelamin \\
\hline tempat_lhr & Text & 30 & Tempat Lahir \\
\hline tgl_lhr & Date/Time & Short Date & Tanggal Lahir \\
\hline agama & Text & 15 & Agama \\
\hline no_telphp & Text & 12 & No Telepon/ Hp \\
\hline nama_ortu & Text & 35 & Nama Orang Tua \\
\hline alamat_ortu & Text & 100 & Alamat Orang Tua \\
\hline kelurahan & Text & 35 & Kelurahan \\
\hline kecamatan & Text & 35 & Kecamatan \\
\hline kabupaten & Text & 35 & Kabupaten \\
\hline kota & Text & 35 & Kota \\
\hline pekerjaan_ortu & Text & 50 & Pekerjaan Orang Tua \\
\hline tahun_masuk & Text & 4 & Tahun Masuk \\
\hline kd_sklh & Text & 15 & Kode Sekolah \\
\hline kd_jurusan & Text & 5 & Kode Jurusan \\
\hline kd_nilai & Text & 5 & Kode Nilai \\
\hline
\end{tabular}

2. Tabel Sekolah

3. Tabel Mata Pelajaran

\begin{tabular}{|l|l|l|l|}
\hline Field Name & Data Type & Size & Deskripsi \\
\hline kd_skh & Text & 15 & Kode Sekolah \\
\hline asal_kkh & Text & 50 & Asal Sekolah \\
\hline kec & Text & 30 & Kecamatan Sekolah \\
\hline kab_kota & Text & 30 & Kabupaten/ Kota \\
\hline
\end{tabular}

\begin{tabular}{|l|l|l|l|}
\hline Field Name & Data Type & Size & Deskripsi \\
\hline kd_matpel & Text & 5 & Kode Mata Pelajaran \\
\hline nama_matpel & Text & 30 & Nama Mata Pelajaran \\
\hline
\end{tabular}

4. Tabel Nilai

\begin{tabular}{|l|l|l|l|}
\hline Field Name & Data Type & Size & Deskripsi \\
\hline Kd_nilai & Autonumber & Long Integer & Kode Nilai \\
\hline no_daftar & Text & 200 & No Daftar \\
\hline Kd_matpel & Text & 200 & Kode Mata Pelajaran \\
\hline nillai_us & Number & Double & Nilai US \\
\hline nilai_un & Number & Double & Nilai UN \\
\hline jmlh_un & Number & Double & Jumlah US \\
\hline jmlh_us & Number & Double & Jumlah UN \\
\hline
\end{tabular}


Perwira Journal of Science and Engineering (PJSE)

E-ISSN : XXXX-XXX

Volume 1 Nomor 1

Februari 2021

5. Tabel Jurusan1

\subsection{Desain Layar Input Proses Output}

\begin{tabular}{|c|c|c|c|}
\hline Field Name & Data Type & Size & Deskininsí \\
\hline Kd julutusan & Text & 5 & Kode Juliusan \\
\hline nama _ulu'tusan & Text & 30 & Nama Iul"LSan \\
\hline
\end{tabular}

1. Desain Layar Log In

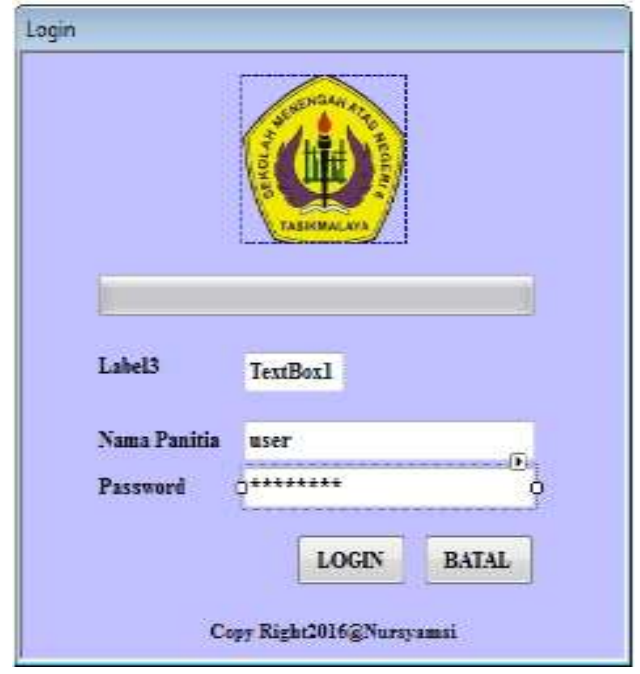

\section{Desain Layar Menu Utama}

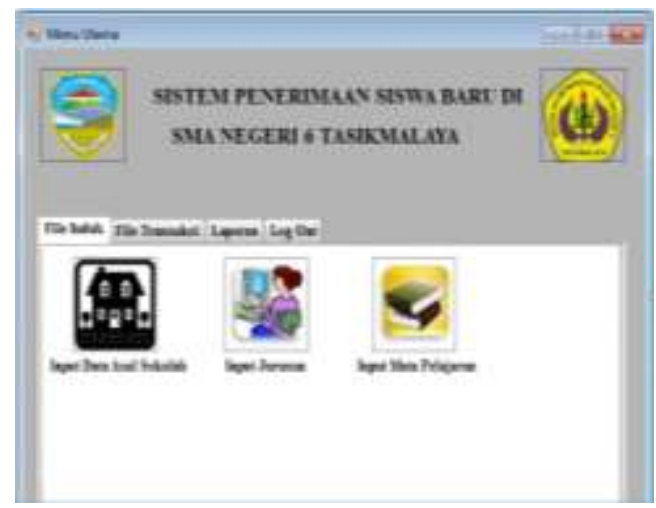


Perwira Journal of Science and Engineering (PJSE)

E-ISSN : XXXX-XXX

Volume 1 Nomor 1

Februari 2021

3. Desain Layar Input Data Asal Sekolah

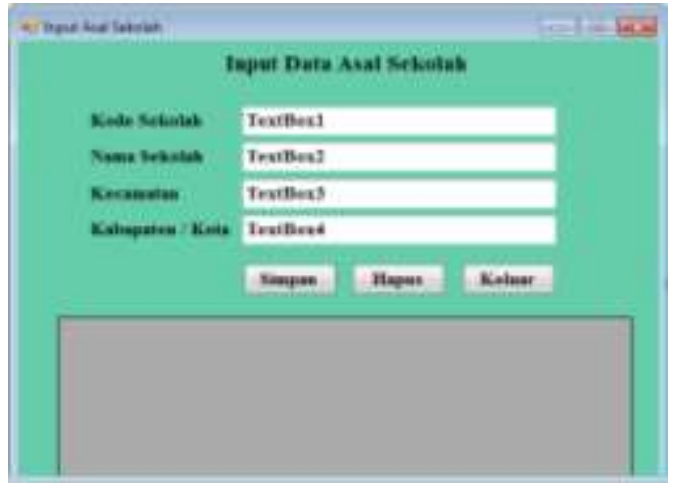

4. Desain Layar Input Jurusan

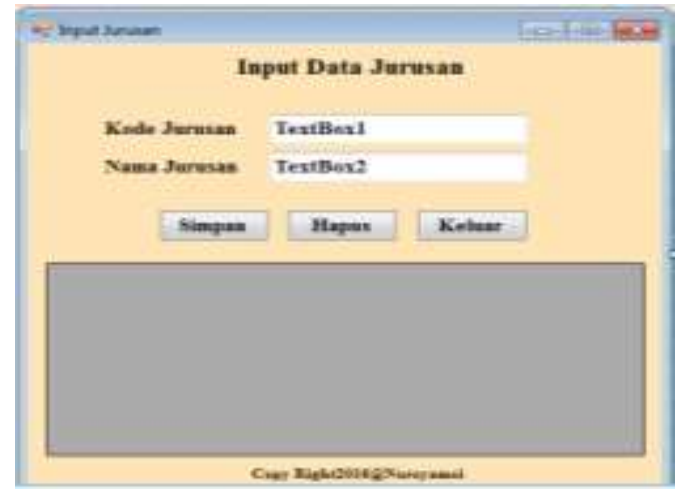

5. Desain Layar Input Mata Pelajaran

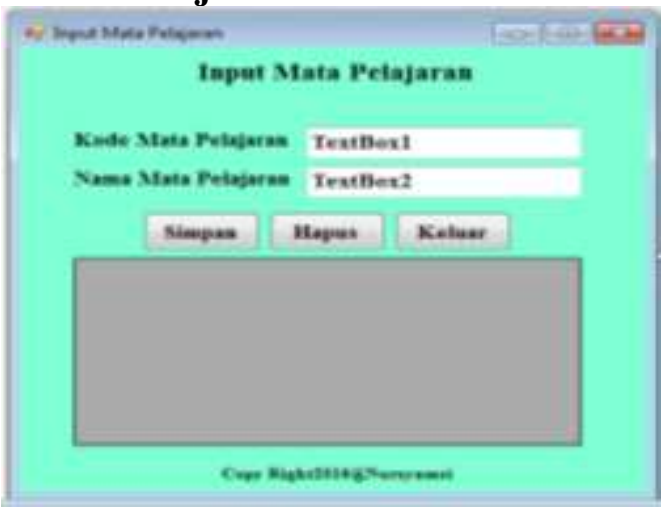

6. Desain Layar Input Penerimaan Siswa Baru

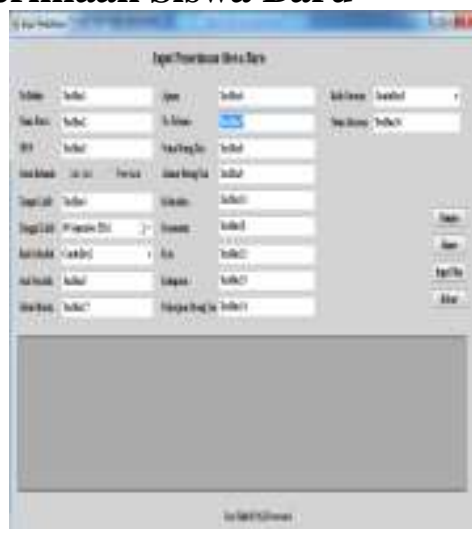


Perwira Journal of Science and Engineering (PJSE)

E-ISSN : XXXX-XXX

Volume 1 Nomor 1

Februari 2021

\section{Desain Layar Input Nilai Siswa}

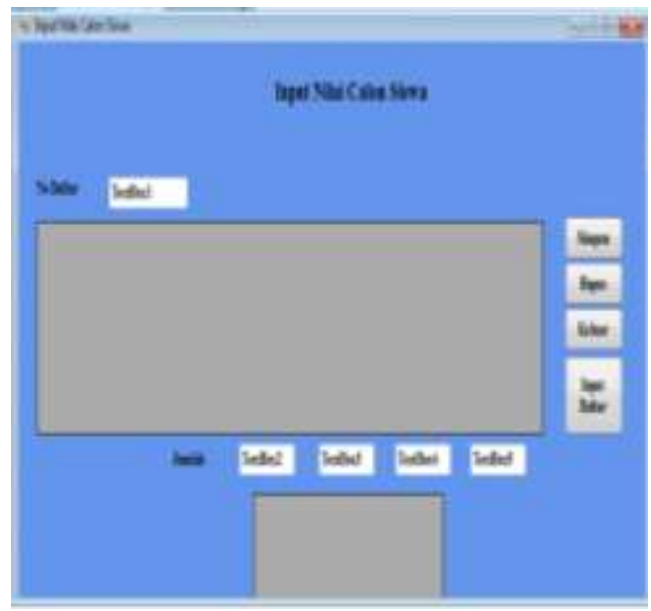

8. Desain Laporan Daftar Peserta Didik Baru

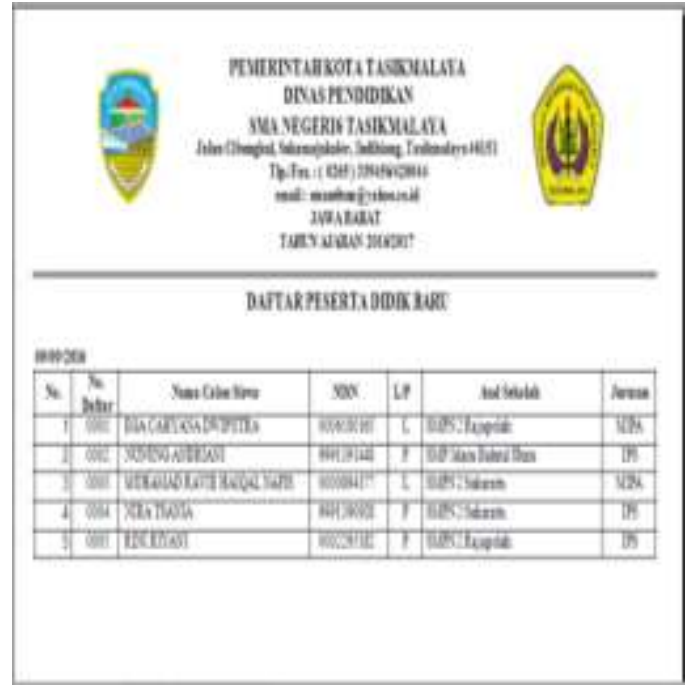

9. Desain Laporan Distribusi Peserta Didik Baru Tiap Jurusan

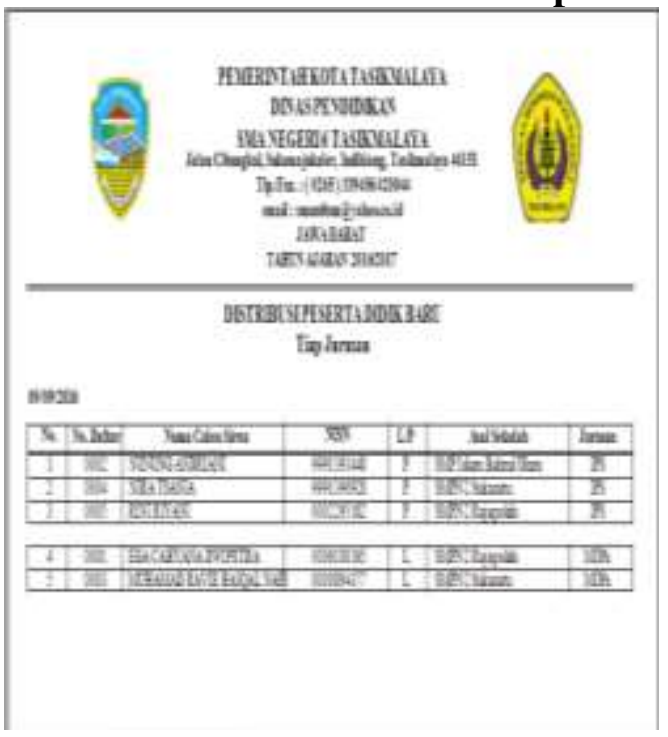


Perwira Journal of Science and Engineering (PJSE)

E-ISSN : XXXX-XXX

Volume 1 Nomor 1

Februari 2021

10. Desain Laporan Laporan Daftar Peserta Didik Baru Berdasarkan Asal Sekolah

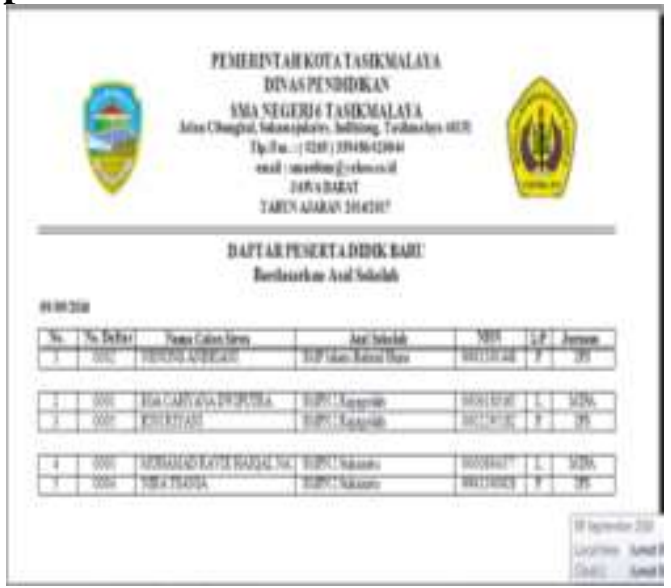

11. Desain Laporan Laporan Daftar Peserta Didik Baru Berdasarkan Nilai

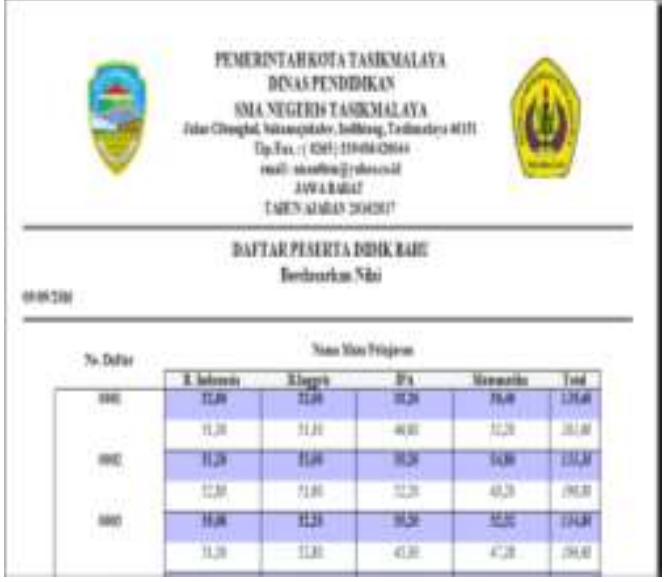

12. Desain Laporan Perkembangan Pendaftar Calon Peserta Didik Baru Tiap Tahun Ajaran

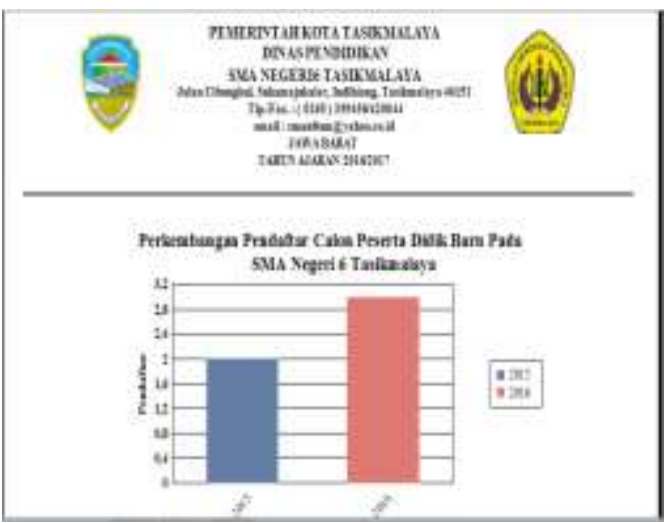

\section{Simpulan Dan Saran}

\subsection{Simpulan}

Setelah mempelajari permasalahan yang dihadapi serta solusi pemecahan masalah yang diajukan, maka dapat ditarik simpulan diantaranya :

1. Bahwa sistem informasi yang sedang berjalan mengenai Penerimaan Siswa Baru di SMA Negeri 6 Tasikmalaya masih bersifat manual, sehingga sering terjadi kesalahan dalam penginputan data. 
Perwira Journal of Science and Engineering (PJSE)

E-ISSN : XXXX-XXX

Volume 1 Nomor 1

Februari 2021

2. Bahwa sistem yang diusulkan penulis benar-benar telah terbukti lebih efektif dan efisien dalam membantu mempermudah dan memperlancar sistem informasi Penerimaan Siswa Baru di SMA Negeri 6 Tasikmalaya.

\subsection{Saran}

Melihat dari simpulan yang di uraikan maka, ada beberapa hal yang harus ditinjau ulang oleh kepala sekolah SMA Negeri 6 Tasikmalaya agar dapat meningkatkan efektifitas dan efisiensi kerja. Diantaranya :

1. Karena sistem yang diusulkan menggunakan Visual Basic .Net 2008 dan Ms. Access yang penulis buat telah terbukti kebenarnya, maka sebaiknya sistem tersebut dapat dipergunakan untuk membantu mempermudah dan memperlancar sistem informasi Penerimaan Siswa Baru di SMA Negeri 6 Tasikmalaya.

2. Menambah fasilitas jaringan untuk mempermudah opersional pengolahan data penerimaan siswa baru di SMA Negeri 6 Tasikmalaya.

\section{Daftar Pustaka}

1. Abdul Kadir. 2003. Pengenalan Sistem Informasi. Yogyakarta: Andi Offset.

2. Bin Ladjamudin, Al Bahra. 2005. Analisis dan Desain Sistem Informasi. Bandung: Graha Ilmu.

3. Davis, Gordon B. 2002. Kerangka Dasar Sistem Informasi Manajemen Bagian II Struktur dan Pengembangannya. Jakarta: PT Bina Print.

4. Edhy Sutanta. 2011. Basis Data dalam Tinjauan Konseptual. Yogyakarta : Andi Offset

5. Edy Winarno, ST. M.Eng., dkk. 2015. Pemrograman Visual Studio .Net untuk Aplikasi Office. Jakarta : PT Elex Media Komputindo.

6. Tata Sutabri, S.Kom., MM. 2005. Sistem Informasi Manajemen. Yogyakarta: Andi Offset.

7. Wing Wahyu Winarno, Drs., MAFIS., Akt. 2006. Sistem Informasi Manajemen. Yogyakarta: UPP STIM YKPN. 